\title{
EVALUATION OF RENAL TUMOUR BY ULTRASOUND AND CT SCAN- A COMPARATIVE ANALYSIS
}

\author{
NP BISWAS ${ }^{1}$, MS ISLAM ${ }^{2}$, MZ HOSSAIN ${ }^{3}$, MH UDDIN ${ }^{1}$, M.A. KASHEM ${ }^{1}$, MS RAHMAN ${ }^{4}$, SAMG KIBRIA ${ }^{4}$, \\ M.S. HASAN ${ }^{4}$
}

\begin{abstract}
:
Purposes: To compare the efficacy of ultrasound and CT scan in renal tumour evaluation and to establish by subsequent histopathology.

Introduction : Renal cell carcinoma accounts for about $3 \%$ of all adult neoplasms. In detecting, characterizing and staging of renal tumours cross-sectional imagings are essential.
\end{abstract}

Methods: In this study 36 cases were selected nonrandomly irrespective of age and sex according to selection criteria. The study was conducted from June 2006 to May 2007 in Banga Bandhu Sheikh Mujib Medical University and other Hospitals in Dhaka City in the department of urology on a quasi- experimental basis. After counselling and taking consent all patients were evaluated clinically and by ultrasound and CT scan. All patients underwent surgery followed by histopathology. All informations were collected in a predesigned data collection sheet. Data were analyzed by computer software program-SPSS version 12 and by manual technique. Comparison and correlation between Ultrasonogram and CT findings were done by Chi-square test. Level of significance was expressed as $P$-value.

Results: Among 36 patients 21 were male and 15 female with a ratio of 1.4:1, age ranging from 3 to 73 years. In this study (from the data) $94.44 \%, 33.33 \%, 89.74 \%$ and $100 \%, 66.66 \% 97.43 \%$ respectively. And there was no statistical significance between these two imaging findings in renal tumour evaluation and $P$-Value was $>$ 0.10 so it was not Significant.

Conclusion : Ultrasonogram and CT Scan are near equivalent to each other evaluation of renal tumour.

Key note: Renal tumour, Ultrasound, CT scan.

\section{Introduction:}

Renal tumours account for about 3\% of all adult neoplasm, and about $85 \%$ of all primary malignant kidney tumous are renal cell carcinoma'. Renal tumours are being recently diagnosed at an earlier stage with greater precision due to the introduction of advanced imaging technology ${ }^{2}$. Renal tumours are frequently identified initially on ultrasound, although CT scan may also be used in the later circumstances of diagnostic uncertainty ${ }^{3}$. Although sonography is an excellent technique for the detection of renal cell carcinoma it can not be used as the sole staging technique ${ }^{4}$.

In poor socioeconomic context of Bangladesh sometimes we have to relay on ultrasound in renal tumour evaluation. So if it is possible to establish the role of ultrasound is equal or near to equal to CT scan in renal tumour evaluation it would be highly appreciable in respect of acceptability, availability, cost-effectiveness, suited for children, pregnant women, and patient with renal parenchymal impairment. Therefore this study was designed to elucidate and compare the roles of ultrasound and CT Scan in renal tumour evaluation.

\section{Materials \& method:}

Initially a total number of 39 patients were selected nonrandomly irrespective of age and sex from June 2006 to May 2007. Out of 39 patients 3 were excluded later on as per exclusion criteria and among rest 36 patients male were 21 , female 15 having age range from 3 to 73 years. The cases were selected with the inclusion criteria having solid lesion of Kidney, complex cystic lesion of Kidney and exclusion criteria having hydronephrosis with or without hydroureter, chronic pyelonephritis, renal abscess renal carbuncle, adrenal tumour and congenital anomalies. All patients were evaluated clinically and by ultrasound and CT scan. They were all admitted in the hospitals department of urology-BSMMU and other hospitals in Dhaka . Surgery performed on them later on with post operative histopathological examination and staging was recorded. Data were collected and analyzed statistically by appropriate statistical methods and level of significance was expressed as P-value. a2 Value was 0.2136 and $p$-value was $>0.10$ so it was not Significant. 


\section{Study design}

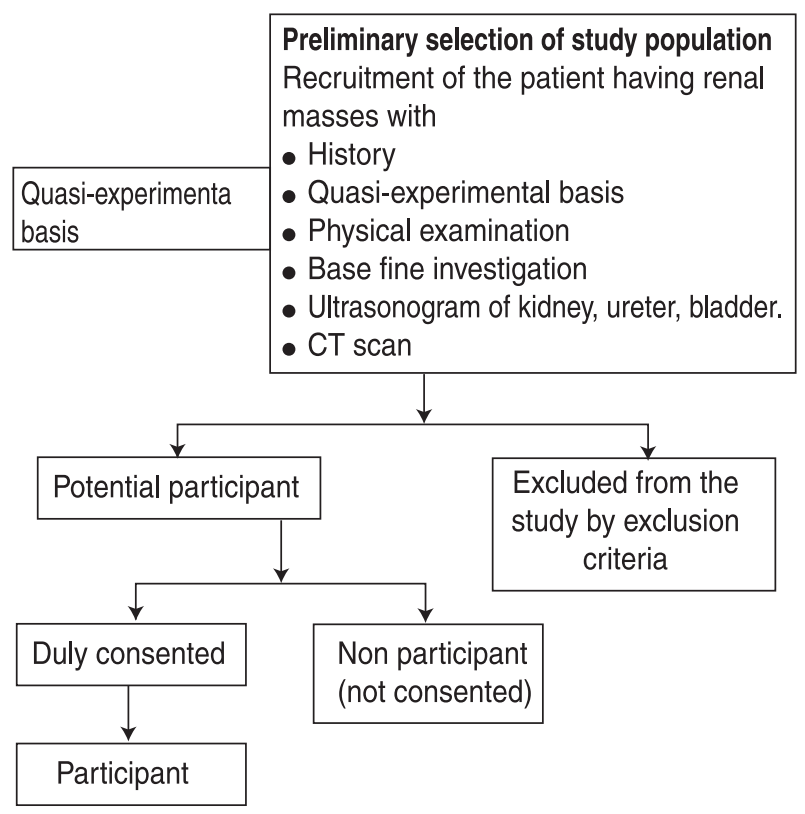

\section{Results and Discussion}

Thirty- nine patients with clinically suspected renal tumour were studied from June 2006 to May 2007. This Study was carried out in the Urology Department of BSMMU, DMCH, NIKDU \& Other hospitals in Dhaka City with Active co-operation of department of pathology and Radiology. Out of 39 patients 36 cases were diagnosed as renal tumours, other 3 cases were diagnosed as suprarenal mass, pyelonephritis and renal absecess; all were confirmed by histopathological examination.

Among the 36 cases with renal tumours, age ranges from 3 to 73 years, the most frequency of malignant

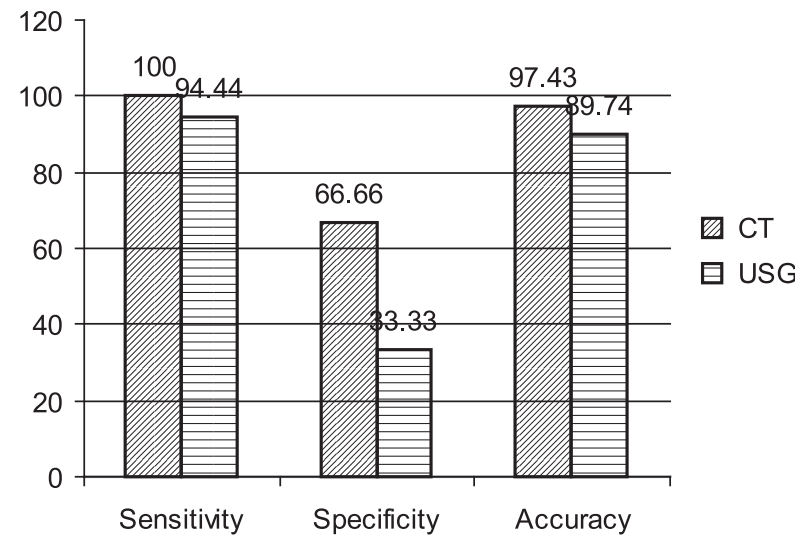

Fig-1 : Shows Sensitivity, Specificany and Accuracy $01 \mathrm{C}$ : 1' scan and Ultrasound in the diagnosis of renal tumour lesion were found in the $5^{\text {th }}$ to $6^{\text {th }}$ decade. In this study 3 cases were found below 10 year of age, all of them were wilms tumour. The peak incidence of malignant lesions was found in the age group around 50 years, sex distribution showed 21 male (58\%) and 15 female $(42 \%)$ with ratio of $1.4: 1$. We found about $25 \%$ patients had loin pain, abdominal pain and lump $44 \%$ and classical triad with $11 \%$ with almost equally distributed between two kidneys. Left Kidney $50 \%$, right Kidney $42 \%$ and bilateral $8 \%$ affected.

Sonographically 19 cases $(52.7 \%)$ wee hypoechoic, of these 16 case $(44.4 \%$ were RCC, 3 cases $(8.3 \%)$ were wilms tumour. Mixed echogenic pattern were seen in 14 cases $(38.8 \%$, which consist of RCC 11 case ( 30.5 $\%)$, case was Wiilms tumour (2.7\%), 1 case was TCC and 1 case $(2.7 \%)$ was leiomyoma. Hyperechoic pattern found case of which 2 were RCC (5.5\%), 1 was angiomyolipoma (2.7\%). In this study there were two false positive case where one suprarenal tumour and another was case of pyelonephritis. There were two false negative results also. False negative examination in Ultrasonography may result from very small lesion, isoechoic mass or Profuse intestinal gas. The sensitivity, specificity, and accuracy of ultrasound were found $94.44 \% 33.33 \%$ and $89.74 \%$ respectively.

Neoplasms may be hypodenseal, isodense, hyperdense or mixed density on CT evaluation. Out of 36 case 27 case $(75 \%)$ were mixed density lesion, all but one case were malignant. All malignant lesions enhanced heterogeneously. Only one case was unenhanced which was diagnosed as angiomyolipoma.

Calcification were seen in 3 cases (8\%), In which 2 cases were RCC I was Wilms tomour. Most of the lesions were more than $3 \mathrm{~cm}$. Only I was $<3 \mathrm{~cm}$, which was missed on ultrasound.

In this study one case was diagnosed as bilateral renal angiomyolipoma. Fat density areas were present within the tumour. After contrast normal renal parenchyma enhanced sparing fat density areas. 4 cases were diagnosed as wilms tumours, 3 cases were paediatric age group but one case was adult. In our study out of 36 cases ultrasound found 2 case $(5.5 \%)$ of venous invasion and 2 case $(5.5 \%)$ of lymph node involvement but in CT 13 cases $(36.1 \%)$ tumours extension were found in perinephric tissue. 2 cases $(5.5 \%)$ were venous invasion, 4 cases $11.1 \%$ were lymph node involvement and 3 cases $(8.3 \%)$ found adjacent organ involvement. The sensitivity, specificity and accuracy of CT scan were found $100 \% 66.66 \%$ and $97 \%$ respectively. 


\section{Conclusion:}

Ultrasound and CT scan are near equivalent to each other in assessing renal tumour in terms of morphology, eco-texture, extension. Ultrasonogram is safe, costeffective, easily available and acceptable to the patients, Higher resolution ultrasound even better than CT scan considering all circumstances.

\section{References:}

1. Patard. J-J, Leclercq RNR, Guille F et al. 2002 Prognostic significance of the mode of detection in renal tumours. BJU International Vol. 90, pp. 358-363.

2. Herts B R 2005. Role of three dimensional imaging in surgical planning for kidney surgery. BJU Int. Vol. 95, pp. 16-20.

3. Pantuck AJ et al. 2001. The changing natural history of renal cell carcinoma. J Urol. Vol. 166, PP. 1611-1623.

4. Rumack C M, Wilson S R, Charboneau JW 2005. Diagnostic Ultrasound. Third Edition, vol. 1, pp 322325.

5. Haubek A, Lundorf E, Laurdsen KN 1991. Diagnostic stratety in renal mass lesions. Send urol Nephrol suppl.: Vol. 137, pp. 35-9
6. Herbert R 1983.. Ultrasonic investigation of the kidneys. Radiography. Vol 49, no. 578, pp. 41-53

7. Coll D M \& Smith R C. 2007. Update on radiological renal cell carcinoma. BJU Int. Vol. 99, pp. 12171222

8. Holmberg G, Hietala SO, Ljungberg B 1988. A comparison of radiologic methods in the diagnosis of renal mass lesions. Send J Urol Nephrol. Vol 22, no. 3, pp. 187-96

9. Raghvendra B N, Bosniak M A. 1983. Small angiolipoma of the kidney: Sonographic-CT evaluation. Am J Roent. Vol. 141, pp. 575-578.

10. Warshauer DM, McCarthy SM, Sreet L et al, 1988. detection of renal masses: sensitivities and specificities of excretory urography/ linear tomography, US and CT. Radiology: Vol 169. pp. 363-365.

11. Zagoria R J, Bechtold RE, Dyer R B 1995. Staging of renal adeocarcinoma: role of various imaging procedures. Am J Roentgenol. Vol. 164, pp. 363370.

\section{Authors}

1. Asstt. Prof. of Urology. SSMC, Mitford Hospital. Dhaka.

2. Asstt. Prof. of Urology. MAG Osmani Medical College, Sylhet

3. Asstt. Prof. of Urology, Rangpur Medical College.

4. Department of urology, BSMMU. 